\title{
Quality of postgraduate medical education
}

\author{
I.G. Nizamov and T.I. Sadykova* \\ Kazan, Russia \\ *Corresponding author. E-mail: sadykovatamara@gmail.com
}

Kazan State Medical Academy, Public Health, Economics and Healthcare Management Sub-faculty;

BACKGROUND: In recent years, huge efforts to improve quality control process and efficiency of healthcare were put in advancing health systems in Russia. There are measurable and noteworthy achievements, there are unresolved issues.

It's impossible to manage the process of improving the quality and efficiency of care without highquality training of respective troops. However, in the last decade a phrase about the poor quality of postgraduate medical education has been heard periodically in the speeches of the leaders at various levels. The source is unknown, but this information continues to be spread by word of mouth as a regular component of speeches about health issues. Considering that the "poor quality" of postgraduate education has not been substantiated by solid evidence, this informational spam, of course, needs to be overcome. It is not only harmful to health system overall, it is harmful in particular for the process of formation of personnel reserve, but it also discredits the whole system of postgraduate education and a titanic work of thousands of teachers, who work as enthusiasts, most of them performing valuable research, teaching and organizational work.

OBJECTIVE: To provide situation analysis in the field of postgraduate medical education.

RESULTS: First of all, it begs the question - how and who measures the quality of education. What indicators in the evaluation process are key? As a rule, when assessing quality in any field, preference is given to the opinion of the consumer.

Our direct customers are the heads of health organs and institutions who regularly undergo advanced training in the specialty "Public Health and Health Care" at sub-faculty. After the completion of each cycle of training and exams, each participant fills out a questionnaire, which points out the level of quality of pedagogical activity of the sub-faculty. The analysis of these questionnaires shows that the students generally give high assessment of the quality of pedagogical process. The health authorities of subjects of Russia that send the heads of their subordinate medical organizations to study public health and healthcare are satisfied with the work of sub-faculty, professorial teaching staff, they send thank-you letters to the educational organization.

In this regard, natural questions related to the overall methodology for the assessment of the quality of education in the system of postgraduate training of doctors arise, which today is still very insufficiently developed.

The quality of education in the system of continuous medical education of physicians can be assessed in the following levels with the help of quality indicators, which have to be developed appropriately for each particular level. In our opinion, the following levels should be included:

1) The level of the sub-faculty

2) The level of the faculty 
3) The level of the medical organization

4) The level of the territorial health authority

5) The level of the subject of the federation.

CONCLUSIONS: Multidimensional assessment of the results of evaluation in the mentioned levels will allow providing an integrated assessment system of quality of continuous medical education in the country.

Keywords: Continuous medical education, quality control, assessments

Conflict of interest statement: None. 